\title{
Biomechanical considerations for uprighting impacted mandibular molars
}

\author{
Yukiko Morita (1) \\ Yoshiyuki Koga (1) \\ Tuan Anh Nguyen \\ Noriaki Yoshida
}

Department of Orthodontics and Dentofacial Orthopedics, Nagasaki University Graduate School of Biomedical Sciences, Nagasaki, Japan
This case report demonstrates two different uprighting mechanics separately applied to mesially tipped mandibular first and second molars. The biomechanical considerations for application of these mechanisms are also discussed. For repositioning of the first molar, which was severely tipped and deeply impacted, a novel cantilever mechanics was used. The molar tube was bonded in the buccolingual direction to facilitate insertion of a cantilever from the buccal side. By twisting the distal end of the cantilever, sufficient uprighting moment was generated. The mesial end of the cantilever was hooked over the miniscrew placed between the canine and first premolar, which could prevent exertion of an intrusive force to the anterior portion of the dentition as a side effect. For repositioning of the second molar, an uprighting mechanics using a compression force with two step bends incorporated into a nickel-titanium archwire was employed. This generated an uprighting moment as well as a distal force acting on the tipped second molar to regain the lost space for the first molar and bring it into its normal position. This epoch-making uprighting mechanics could also minimize the extrusion of the molar, thereby preventing occlusal interference by increasing interocclusal clearance between the inferiorly placed two step bends and the antagonist tooth. Consequently, the two step bends could help prevent occlusal interference. After 2 years and 11 months of active treatment, a desirable Class 1 occlusion was successfully achieved without permanent tooth extraction.

[Korean J Orthod 2020;50(4):268-277]

Key words: Orthodontic treatment, Orthodontic implant, Impacted molars, Mechanics

Received January 16, 2019; Revised March 3, 2019; Accepted March 8, 2019.

Corresponding author: Yoshiyuki Koga.

Senior Lecturer, Department of Orthodontics and Dentofacial Orthopedics, Nagasaki University Graduate School of Biomedical Sciences, 1-7-1 Sakamoto, Nagasaki 852-8588, Japan.

Tel +81-95-819-7669 e-mail koga@nagasaki-u.ac.jp

How to cite this article: Morita Y, Koga Y, Nguyen TA, Yoshida N. Biomechanical considerations for uprighting impacted mandibular molars. Korean J Orthod 2020;50:268-277.

(C) 2020 The Korean Association of Orthodontists.

This is an Open Access article distributed under the terms of the Creative Commons Attribution Non-Commercial License (http://creativecommons.org/licenses/by-nc/4.0) which permits unrestricted non-commercial use, distribution, and reproduction in any medium, provided the original work is properly cited. 


\section{INTRODUCTION}

Although the prevalence of third molar impaction is relatively high, first molar impaction is extremely rare and has extremely complex treatment mechanisms. ${ }^{1-3}$ Permanent tooth impaction frequently causes occlusal problems in which the adjacent tooth tends to be inclined into the impacted tooth site, and the opposing tooth tends to be over-erupted. In order to correct such a posterior bite collapse orthodontically, an appropriate force system should be delivered to each tooth. There are two general methods for uprighting molars. One involves a cantilever mechanics, which is often used to effectively upright the molars, and it simultaneously generates an extrusive force as well as a distal tipping moment. ${ }^{4,5}$ Therefore, this mechanics is indicated for the correction of severely tipped and deeply impacted molars. The other is a mechanics that uses a compression force generated with an open-coil spring. ${ }^{6}$ This generates a distal force to the tipped molar, which could regain the lost space, and a distal tipping moment due to a distal force passing above the center of resistance (CR) of the molar.

Although many case reports have described the conventional orthodontic treatment of mesially inclined impacted molars, ${ }^{7-15}$ there are few reports describing the biomechanical considerations for delivering an optimal force system. When the cantilever mechanics is used, the tipped molar is subjected to not only an uprighting moment, but also an extrusive force, which could cause occlusal interference with the opposing tooth. Additionally, an intrusive force is applied to the teeth on which the mesial end of the cantilever is hooked as a side effect.

In order to minimize these adverse effects during molar uprighting, the use of several types of orthodontic mechanics with temporary anchorage devices (TADs) has been advocated. ${ }^{16-23}$ However, even with TADs, unwanted side effects cannot be completely avoided, and the treatment mechanics required to produce an optimal force system tend to be complicated. ${ }^{23}$

This case report describes an effective treatment option with well-designed simple mechanics including a novel cantilever system using TADs and uprighting mechanics using a compression force with two step bends incorporated into a nickel-titanium (NiTi) archwire.

\section{DIAGNOSIS AND ETIOLOGY}

A 13-year-old Japanese girl with a slight Class 11 molar relationship visited the Department of Orthodontics, Nagasaki University Hospital. Her chief complaints were delayed eruption of the left mandibular first molar and occlusal pain in the same region. Intraorally, all of the permanent teeth from the right first molar to the left first molar were fully erupted, except the left mandibular first molar, and the mandibular left second molar was partially erupted. A slight mid-line diasthema was observed. The over-erupted maxillary left first molar was occluded with the mandibular gingiva (Figures 1 and 2).

A panoramic radiograph obtained before treatment showed the presence of the left mandibular first and second molars with severe mesial inclination and the

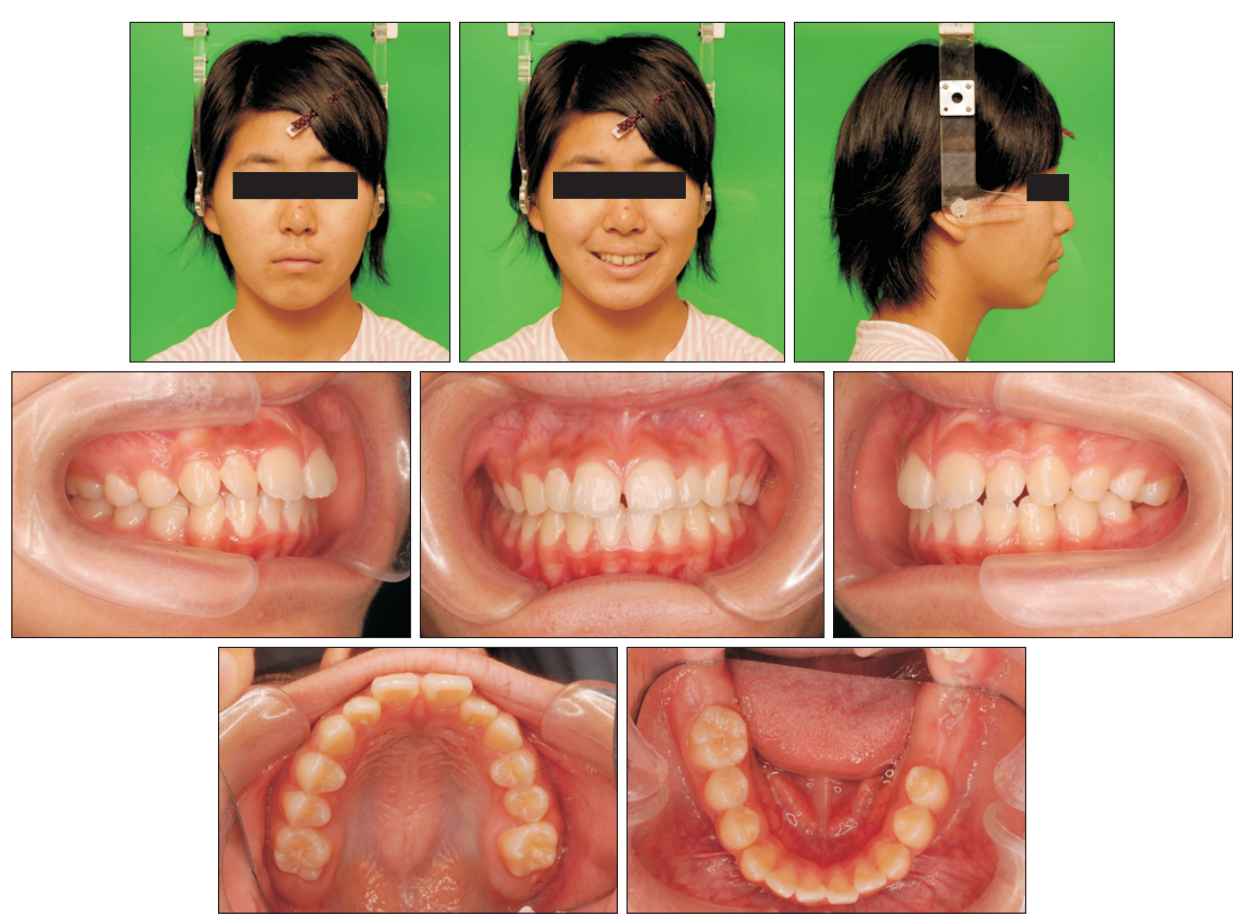

Figure 1. Pretreatment facial and intraoral photographs. 


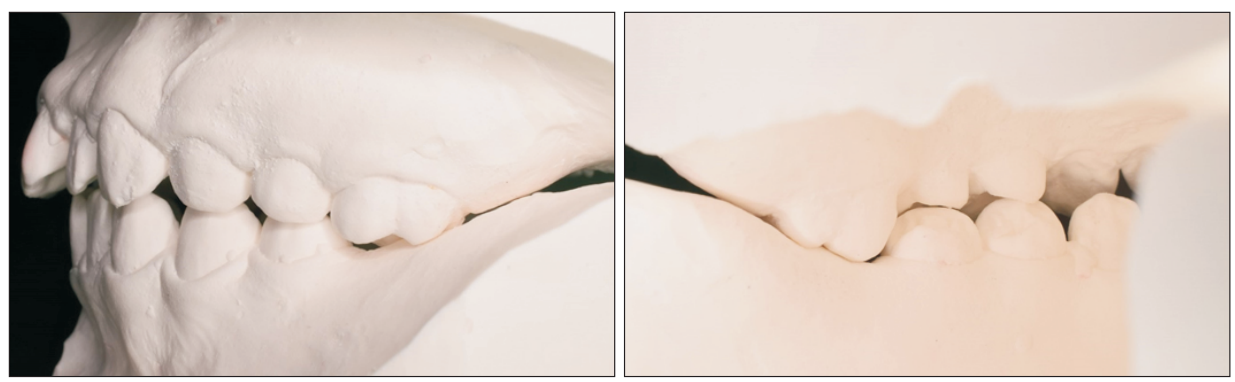

Figure 2. Pretreatment study model: over-erupted maxillary left first molar occluding onto the mandibular gingiva. four developing third molar buds (Figure 3).

\section{TREATMENT OBJECTIVES}

The treatment objectives were to establish the left posterior occlusion, which included the over-erupted maxillary first molar and the impacted mandibular molars, and to also establish interdigitation of the maxillary and mandibular dentition and a Class 1 molar relationship.

The treatment plan consisted of four stages. The first stage was intrusion of the left maxillary first molar to acquire the lost interocclusal clearance for uprighting and bringing the left mandibular first molar into occlusion. The second stage was uprighting and distalization of the left mandibular second molar to gain the space for the first molar. The third stage was uprighting of the left mandibular first molar following surgical exposure. The last stage was alignment of the maxillary arch and establishment of proper molar interdigitation and a Class 1 molar relationship.

The pretreatment panoramic radiograph and a schematic diagram indicating treatment objectives and force systems acting on the molars are shown in Figure 4A and $4 \mathrm{~B}$. Before uprighting of the impacted molars, the over-erupted maxillary first molar, which was the opposed tooth on the opposite side, was to be intruded by $3 \mathrm{~mm}$ to the level of the maxillary occlusal plane (Figure 4B). The mandibular first molar was to be uprighted by $60^{\circ}$ and extruded by $6 \mathrm{~mm}$ at the location of its $\mathrm{CR}$, and the second molar was to be uprighted by $30^{\circ}$ and extruded by $1 \mathrm{~mm}$.

\section{TREATMENT ALTERNATIVES}

One treatment option could be extraction of the impacted first or second molar, since the first molar was severely inclined mesially and deeply impacted, and the second molar was also tipped mesially and disturbed the eruption of the first molar. Extraction of the impacted molar could cause substantial bone loss in the extraction area and result in a prolonged treatment time due to the need to wait for the full eruption of the third molar.
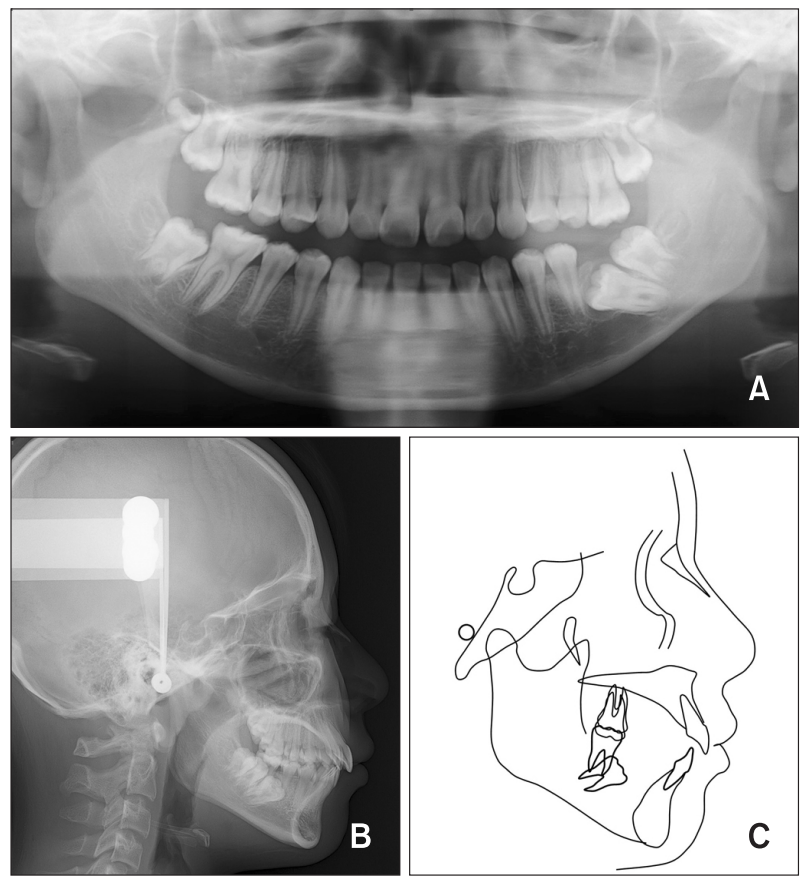

Figure 3. Pretreatment. A, Panoramic radiograph; B, lateral cephalometric radiographs; $\mathbf{C}$, cephalometric superimposition.

The other treatment option was non-extraction and uprighting of both molars using TADs. The latter treatment option was selected, since it is less invasive and was a reversible approach unlike molar extraction. In this case, there are two options for miniscrew placement sites for molar uprighting, i.e., either anteriorly or posteriorly to the left mandibular molars. To extrude and upright, a miniscrew was inserted anteriorly.

\section{TREATMENT PROGRESS}

For intrusion of the left maxillary first molar, one miniscrew (Dual-Top Anchor Screw; Jeil Medical Co., Seoul, Korea) was inserted in the interradicular space between the left second premolar and first molar on the palatal side. Another miniscrew was placed between the left mandibular canine and first premolar on the 

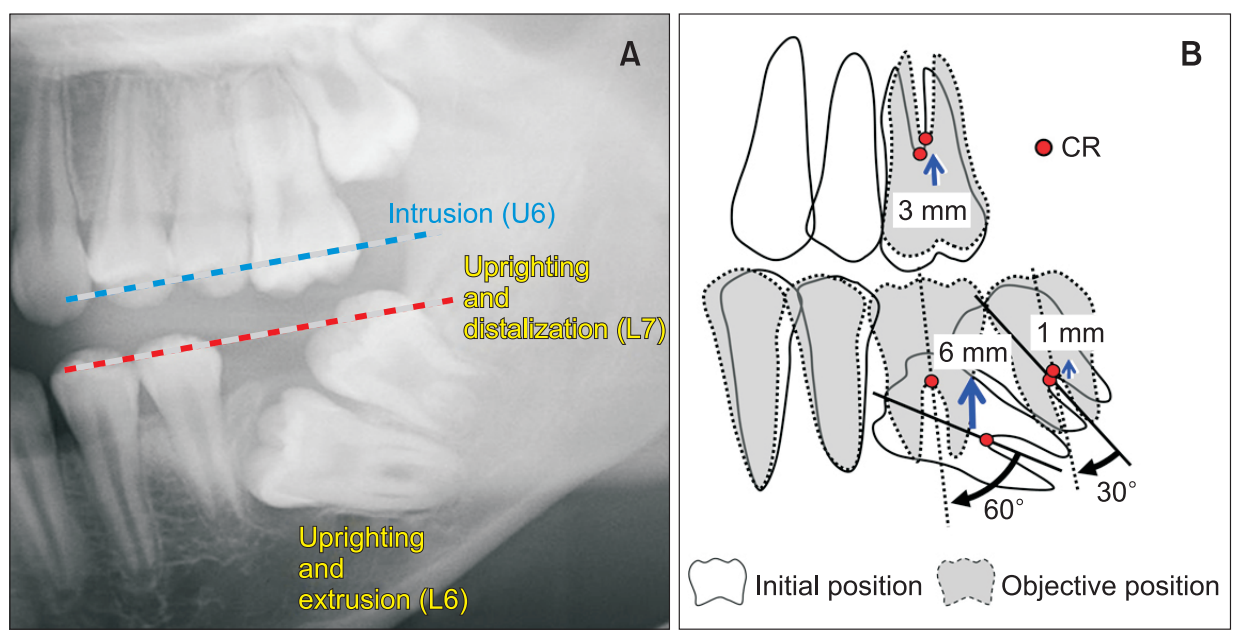

Figure 4. Treatment objectives. A, Treatment plan for repositioning of the molars. $\mathbf{B}$, Schematic diagram of treatment objectives. The maxillary first molar is intruded by 3 $\mathrm{mm}$. The mandibular first and second molars are uprighted by $60^{\circ}$ and $30^{\circ}$, and extruded by $6 \mathrm{~mm}$ and $1 \mathrm{~mm}$, respectively. U6, Upper first molar; L6, lower first molar; L7, lower second molar; CR, center of resistance.
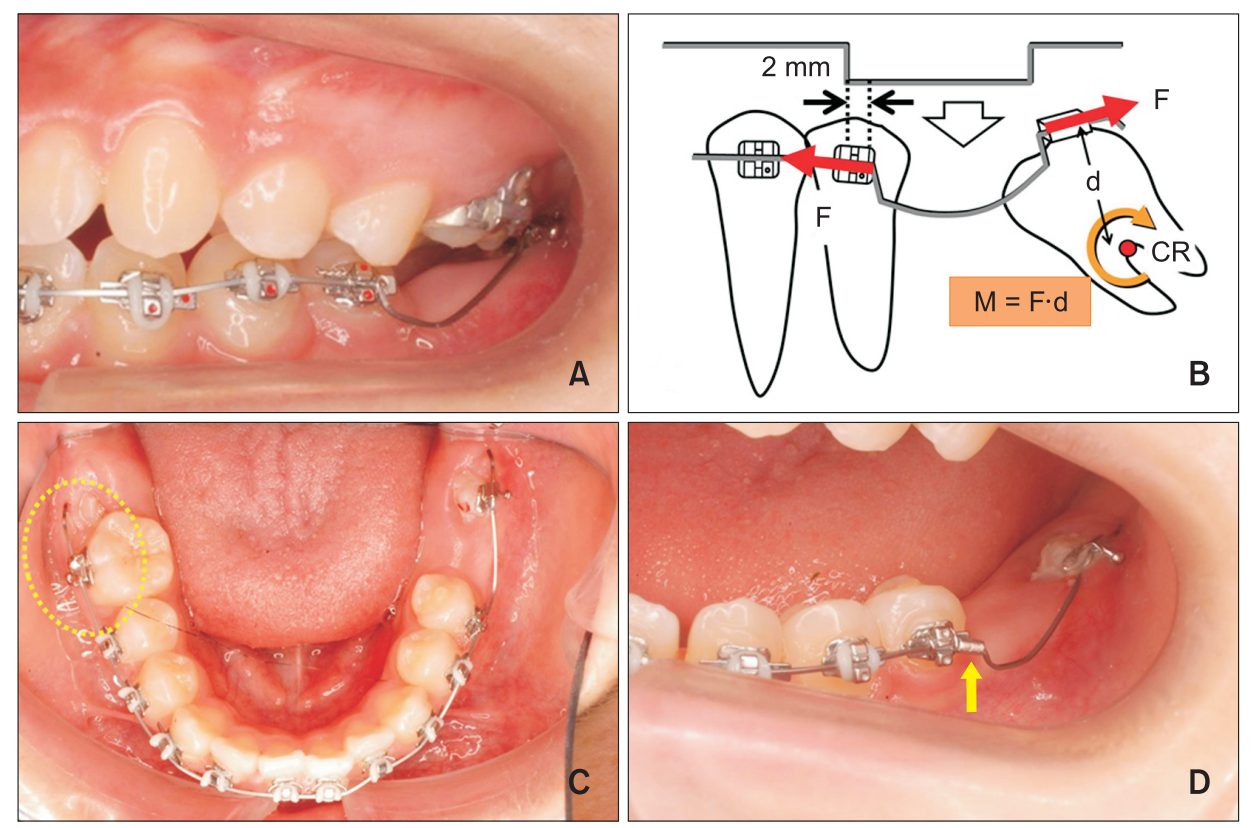

Figure 5. Progress and force system for uprighting the mandibular second molar. A, Left mandibular second molar uprighting using a $0.016 \times 0.016$-inch (in) square nickel-titanium (NiTi) archwire with two step bends whose distance was 2 $\mathrm{mm}$ wider than the inter-bracket distance between the left second premolar and the second molar. B, Force system acting on the second molar when the uprighting mechanics using a compression force is employed. Two step bends, whose distance is $2 \mathrm{~mm}$ wider than the inter-bracket distance between the second premolar and second molar, are incorporated into a $0.016 \times 0.016$-in square NiTi archwire. When the two step bends incorporated into the archwire are squeezed and engaged into the brackets, a mesial force to the second premolar and a distal force to the second molar are generated. Then, an uprighting moment (M), whose magnitude is the product of the magnitude of the distal force (F) and the perpendicular distance (d) from its line of force to the center of resistance (CR), is produced. C, The length of the excess wire distal to the buccal tube on the right first molar was used to shift the archwire to the left to reactivate the two step bends without removing the archwire (circle). D, A crimpable stop placed on the archwire just mesial to the anterior step bend (arrow).

buccal side. A transpalatal arch (3D Palatal Appliance; Rocky Mountain Orthodontics, Denver, CO, USA) was placed to minimize the undesirable buccolingual tipping of the molars during intrusion. Intrusion of the overerupted left maxillary first molar was started by applying an elastomeric chain from the hook soldered to the 
transpalatal arch to the miniscrew. After 6 months of molar intrusion, vertical clearance of $4 \mathrm{~mm}$ between the left maxillary first molar cusp and the mandibular gingiva was obtained (Figure 5A).

The left second molar was first uprighted to regain the space for eruption of the first molar. In order to upright the second molar, a novel and unique mechanics was used. In this mechanics, two step bends, whose distance was $2 \mathrm{~mm}$ wider than the inter-bracket distance between the second premolar and second molar, were incorporated into a $0.016 \times 0.016$-inch (in) NiTi archwire, and then squeezed and engaged into the bracket and tube. Since a compression force was produced between the two teeth, the second molar was subjected to a distal force (Figure $5 \mathrm{~A}$ and $5 \mathrm{~B}$ ).

The advantage of this archwire with two step bends is that its reactivation can be performed without removing the archwire. The excess wire distal to the buccal tube on the right first molar was left for the subsequent patient visits. On the next visit, the archwire was shifted to the left, and the distal end of the archwire was slid through a tube on the left second molar. The excess wire distance was used to create the space for placing a crimpable stop onto the archwire just mesial to the anterior step bend to reactivate the two step bends (Figure 5C and 5D). Three months after the left second molar uprighting was started, the archwire was changed to a heat-treated $0.017 \times 0.022$-in Elgiloy archwire. The second molar was successfully uprighted into its normal position, and sufficient space for eruption of the first molar was gained in 6 months.

In order to upright and extrude the first molar, surgical exposure of its crown was performed by an open window procedure and a small molar tube (AP Terminal tubes; TOMY International Inc., Tokyo, Japan) bonded in the buccolingual direction on the distal surface of the
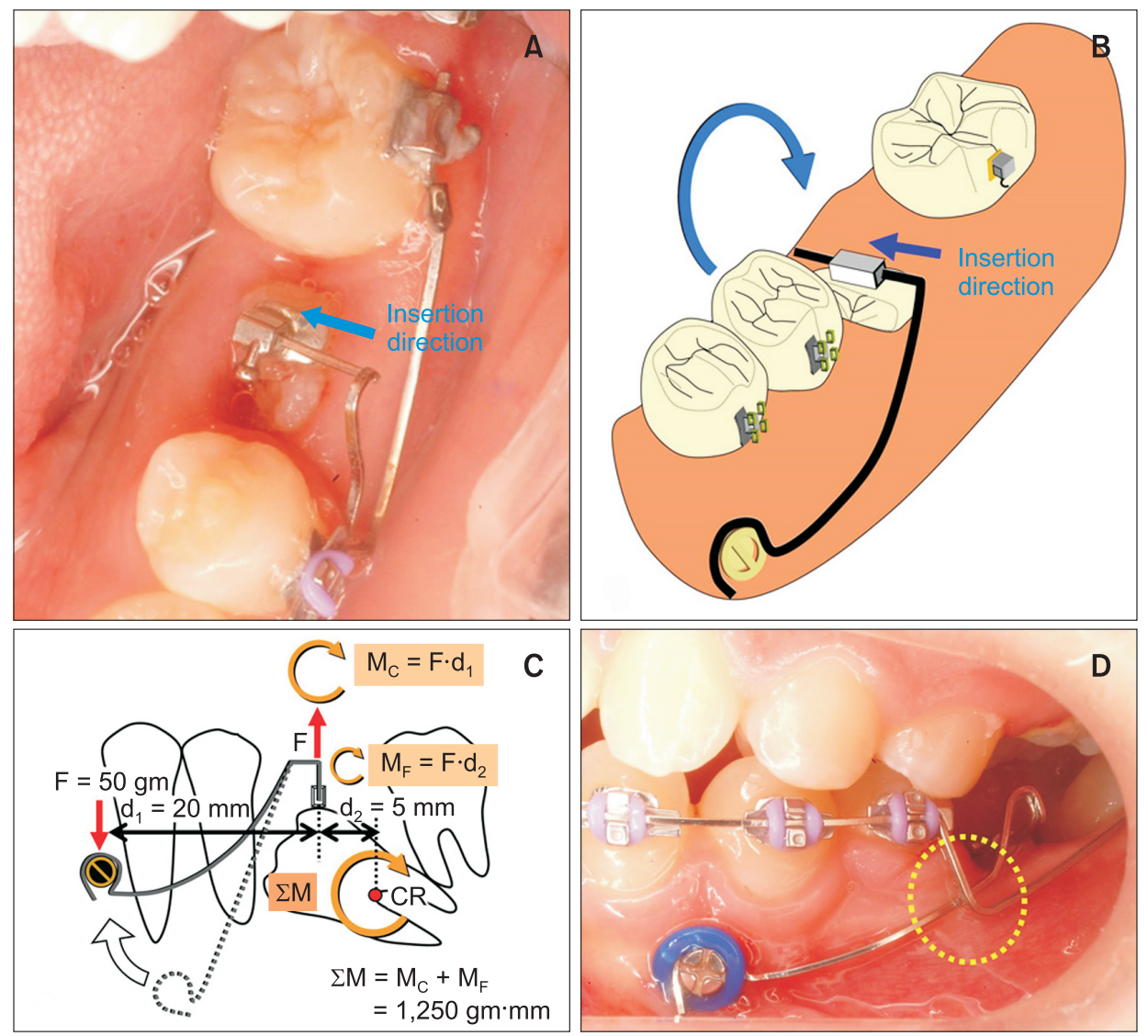

Figure 6. Treatment mechanics for uprighting of the left mandibular first molar. A, B, A small molar tube bonded buccolingually and an arrow indicates the insertion direction of the cantilever. $\mathbf{C}$, Force system acting on the first molar and miniscrew when the cantilever mechanics is employed. A dotted line indicates the cantilever in its passive state, and a solid line in its active state. When the cantilever is activated, a moment of couple $\left(\mathrm{M}_{\mathrm{C}}\right)$ to tip the molar distally, an extrusive force on the molar tube, and an intrusive force on the miniscrew are generated. The uprighting moment acting on the molar is the sum of $\mathrm{M}_{\mathrm{C}}$ and the moment of force $\left(\mathrm{M}_{\mathrm{F}}\right)$. $\mathbf{D}$, The cantilever passes under the main archwire to avoid slipping buccally and the mesial end of the cantilever hooked over the miniscrew (circle). 
exposed part, which facilitated insertion of an auxiliary uprighting cantilever from the buccal side (Figure 6A and $6 \mathrm{~B})$. A moment for the molar uprighting was efficiently produced by twisting the distal end of the cantilever (Figure 6B and 6C). Since the cantilever should be kept stable in the oral cavity without coming out of the tube, the middle part of the cantilever was passed under the main archwire. Then, the mesial end of the cantilever was formed in a semicircular shape and hooked over the head of the miniscrew that was inserted between the canine and first premolar (Figure 6D).

At 8 months (6 months with the auxiliary spring and 2 months with the main archwire) from the beginning of correction of the impacted first molar, alignment of the teeth of the left mandibular molar area was successfully completed (Figure 7), after which the alignment of the maxillary dentition was started, thereby avoiding the risk of undesired collision between the maxillary and mandibular molars during their uprighting. To correct the molar relationship, the right maxillary quadrant was
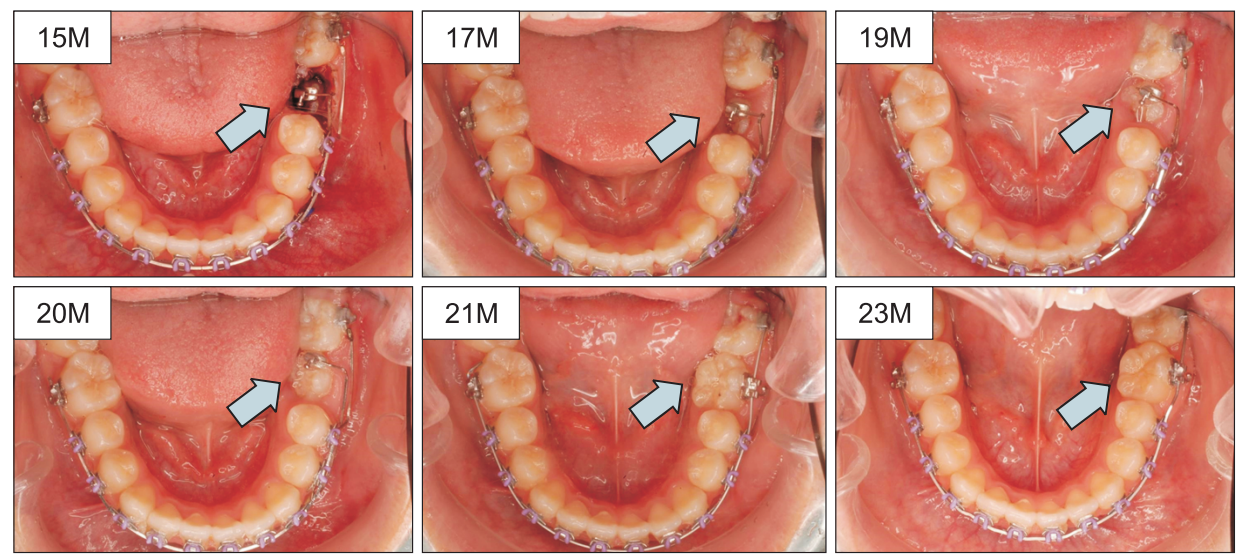

Figure 7. The treatment sequence for uprighting of the left mandibular first molar (the blue arrow indicated) $(15 \mathrm{M} ; 15$ months after orthodontic treatment started). Progress is shown at treatment times in months. The archwire was $0.017 \times$ 0.022 -inch (in) Elgiloy and a $0.016 \times 0.022$-in stainless steel cantilever was used for uprighting the left mandibular first molar. At 21 months, a molar tube was bonded on the buccal surface of the first molar and the 0.018-in nickel-titanium archwire was engaged for its alignment.
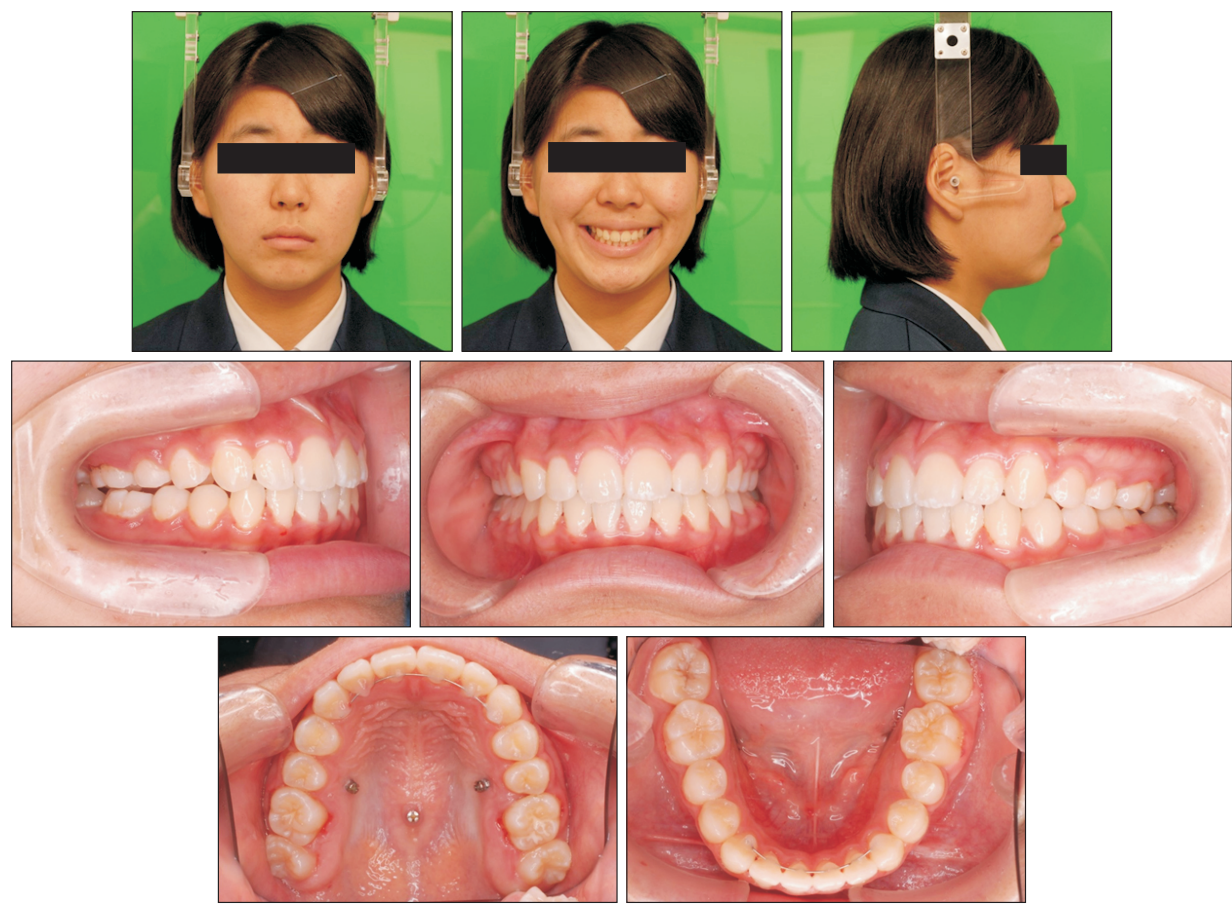

Figure 8. Posttreatment facial and intraoral photographs. 

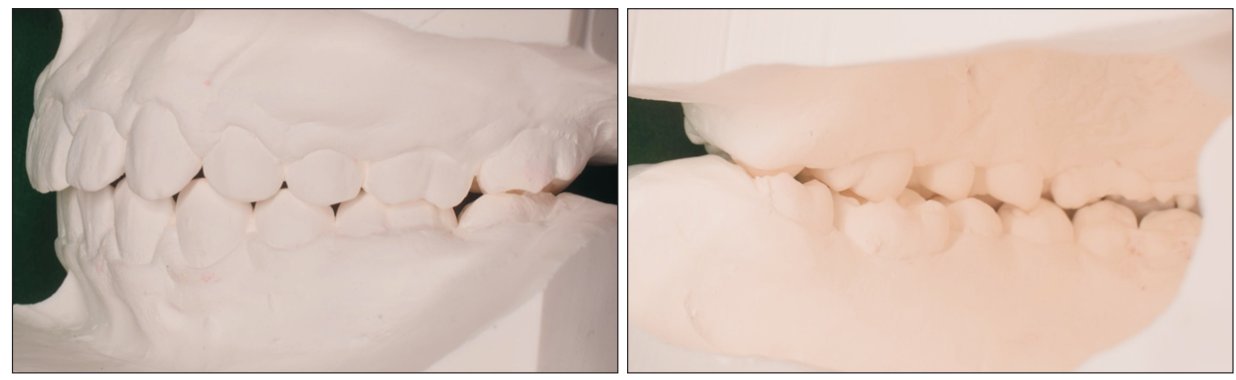

Figure 9. Posttreatment study model: the left posterior occlusion is normalized.

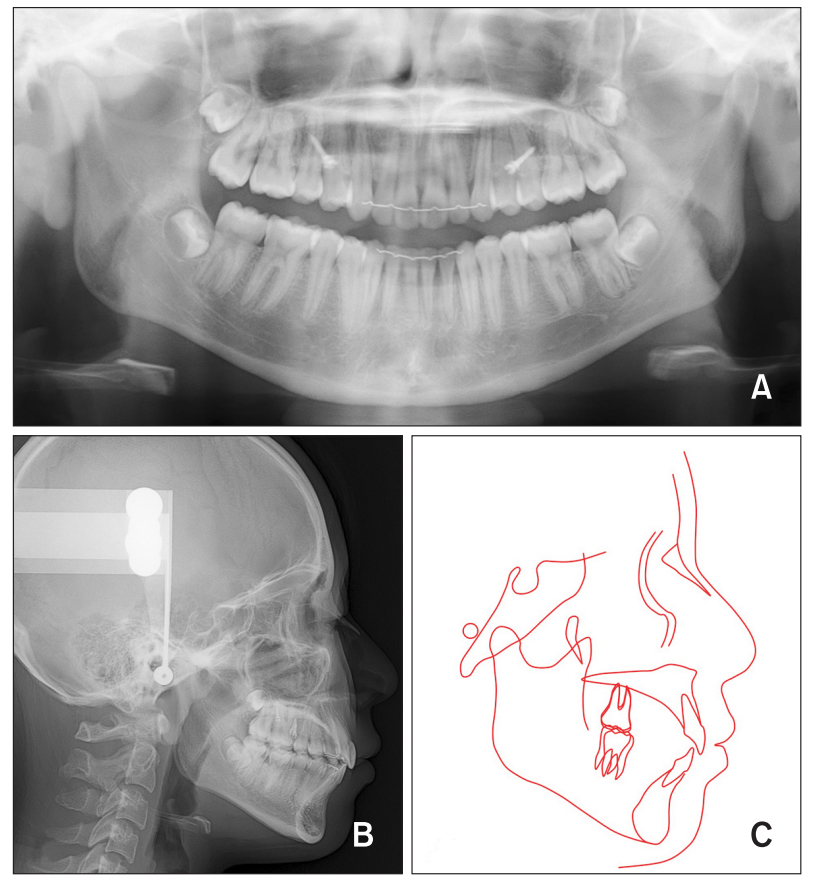

Figure 10. Posttreatment. A, Panoramic radiograph; B, lateral cephalometric radiograph; $C_{\text {, tracing. }}$

moved distally with combined use of the transpalatal arch and the miniscrews. In one year of additional treatment, proper overjet and overbite were obtained, and a bilateral Class 1 canine and molar relationship was established. Anterior lingual fixed retainers were placed in both jaws after appliance removal.

\section{TREATMENT RESULTS}

The left mandibular first and second molars were successfully uprighted, and the occlusion of the left posterior region was established (Figures 8 and 9). Overjet and overbite were adequate, and occlusal interdigitation of the maxillary and mandibular dentition and a Class 1 molar relationship were established (Figures 8 and 10). The posttreatment panoramic radiograph showed acceptable root parallelism with no significant sign of bone or root resorption (Figure 10A). A cephalometric
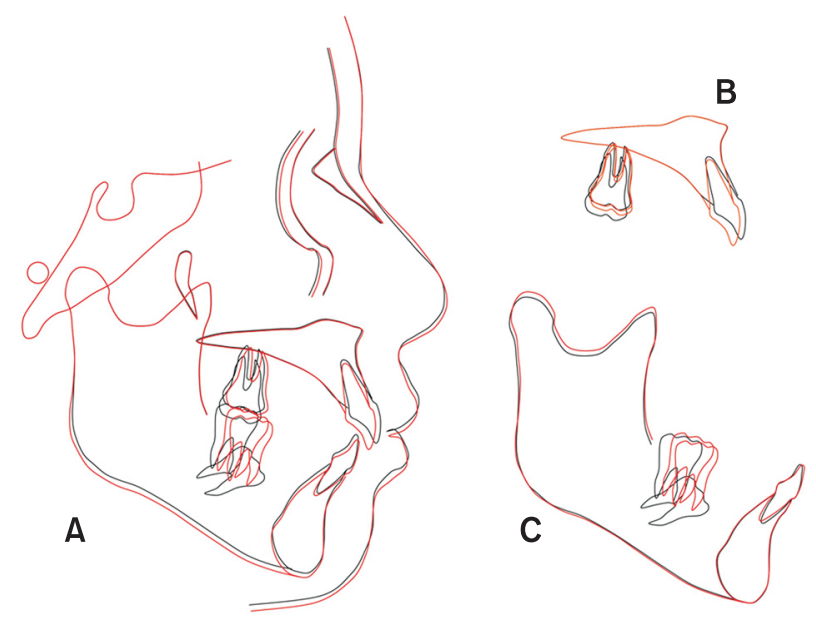

Figure 11. Superimposition of the pretreatment and posttreatment lateral cephalometric radiographs. $A_{1}$ On the sella-nasion plane at sella; $\mathbf{B}$, on the palatal plane at anterior nasal spine; $\mathbf{C}$, on the mandibular plane at the menton.

Black line, Pretreatment; Red line, posttreatment.

superimposition demonstrated that the left maxillary first molar was intruded by $3 \mathrm{~mm}$ (Figure 11B), and the left mandibular first molar was uprighted by $60^{\circ}$ and extruded by $6 \mathrm{~mm}$ (Figure 11C). The total treatment period was 2 years 11 months. The patient maintained good occlusion for 2 years after the end of active orthodontic treatment (Figure 12).

\section{DISCUSSION}

In the present case, the patient had three major dental problems associated with collapse of the posterior occlusion on the left side: severely tipped and deeply impacted mandibular left first molar, partially impacted and mesially tipped second molar overhanging the adjacent first molar, and a maxillary first molar that was elongated into the edentulous space occluding with the mandibular gingiva.

There are two options for the miniscrew placement site for molar uprighting. Molar uprighting with a mini- 


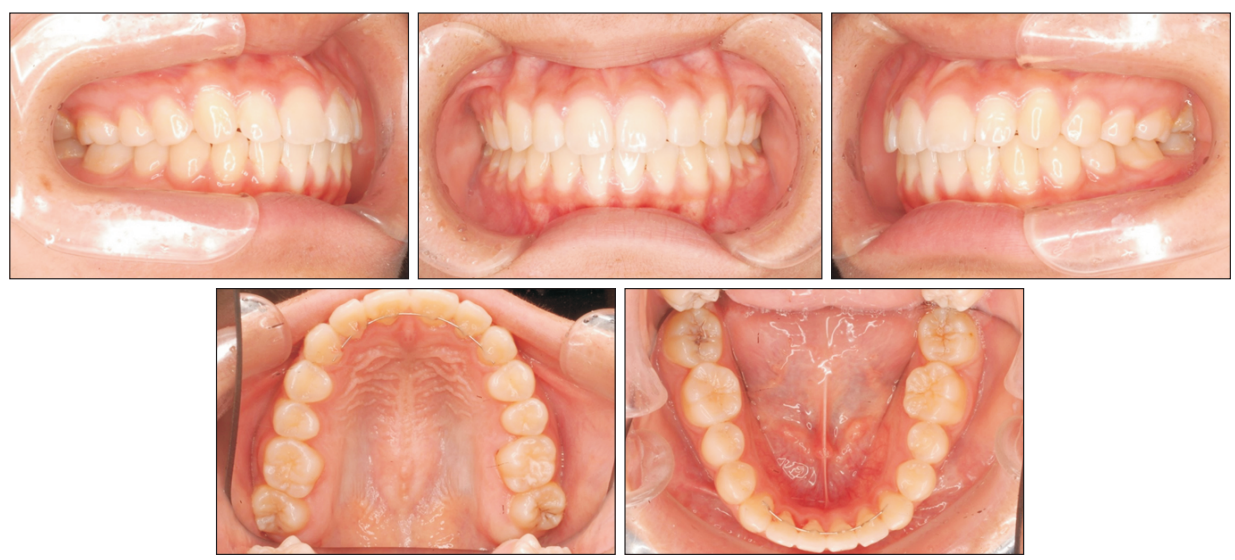

Figure 12. Intraoral photographs obtained 2 years after orthodontic treatment. screw inserted in the mandibular retromolar area could simplify the mechanics by hooking an elastomeric chain between the miniscrew head and an attachment on the molar crown. ${ }^{16-19}$ However, impacted molar teeth, especially the first molar, might be subjected to a distal force depending on its location using this mechanics. In the present case, a distal force could not be applied to the first molar, since the first molar was deeply impacted and tipped mesially, and its CR was located distally as compared to its ideal position (Figure 4B). Therefore, the placement of a miniscrew in the retromolar area was considered to be unsuitable for the present case. Moreover, the soft tissue of the retromolar area is movable and a miniscrew head might be more easily covered by mucosa, potentially causing patient discomfort and gingival inflammation, which should be prevented to ensure stability of the miniscrews. ${ }^{24-27}$

On the other hand, when a miniscrew is placed anteriorly to the target molar, the uprighting cantilever mechanics can be used. For uprighting and extruding the first molar in this case, an uprighting cantilever was used, since the cantilever mechanics will produce an uprighting moment and extrusive force simultaneously, which is suitable for correction of the angulated and inferiorly positioned molar. When a mesial end of the uprighting cantilever is directly hooked onto a main archwire in a conventional method, an intrusive force is applied as a reaction force at the point of force application on the wire, which could collapse the occlusal interdigitation. To prevent this adverse effect, a miniscrew was inserted between the canine and the first premolar, and the cantilever was hooked over the miniscrew head (Figure 6B).

The most unique aspect of the molar uprighting mechanics used in the present case was the attachment of a tube in the buccolingual direction instead of the mesiodistal direction as is usually performed. If the molar is deeply impacted and tipped mesially, it becomes quite difficult to attach a tube onto the buccal surface in the mesiodistal direction due to the limited exposed area on the crown. On the other hand, placement of a tube in the buccolingual direction could facilitate the bonding process and insertion of the right-angled distal end of the uprighting cantilever from the buccal side (Figure 6A). An effective distal tipping moment can be applied to the molar by twisting the distal end of the cantilever (Figure 6B). ${ }^{20}$

Since the first molar was to be uprighted by $60^{\circ}$, an extremely large amount of root movement was necessary; therefore, a substantial distal tipping moment had to be applied. There are two options for the insertion site of the miniscrew, either between the canine and premolar or between the first and second premolars. The length of the cantilever varies depending on the location of the miniscrew. The more anteriorly a miniscrew is placed, the longer the cantilever length, which produces a larger uprighting moment acting on the molar. For this reason, a miniscrew was inserted between the canine and first premolar to establish a longer cantilever mechanics (Figure 4).

Figure $6 \mathrm{C}$ shows a force system acting on the first molar and miniscrew or the activated cantilever in static equilibrium. To satisfy the conditions for equilibrium, a pair of vertical forces (F) equal in magnitude and opposite in direction were generated, making their sum with the moment of couple $\left(\mathrm{M}_{\mathrm{C}}\right)$ equal to zero. The total amount of distal tipping moment $(\Sigma \mathrm{M})$ acting on the molar can be calculated as the sum of the moment of the couple and the moment of the force. The amount of $\mathrm{M}_{\mathrm{C}}$ is expressed by the product of the amount of the vertical force ( $\mathrm{F}$ : extrusive force on the molar or intrusive force on the miniscrew) and the distance from the miniscrew to the molar tube $\left(d_{1}\right)$, and the amount of the moment of force $\left(\mathrm{M}_{\mathrm{F}}\right)$ is expressed by the product of the amount of the vertical force and the perpendicular distance from a line of action of the force on the molar to its $C R\left(d_{2}\right)$. If an uprighting cantilever is activated such that an extrusive force of $50 \mathrm{gm}$ is produced, the 
amount of distal tipping moment is calculated to be $1,250 \mathrm{gm}-\mathrm{mm}$. If the miniscrew is placed between the first and second premolars, the distance between the miniscrew and the molar tube reduces, and the amount of uprighting moment is decreased as a result. In other words, when a certain amount of uprighting moment is required to be applied, a larger amount of extrusive force is generated, which may cause occlusal interference with the maxillary molar. When the molar is severely inclined, it is recommended to place the miniscrew more anteriorly and secure a long cantilever length to produce an adequate uprighting moment.

Regarding the stability of miniscrews depending on their insertion sites, Chang et al. $^{28}$ suggested that the failure rate for miniscrews inserted in the interradicular space is higher than that in the retromolar area. Nevertheless, we prioritized the use of the cantilever mechanics considering its biomechanical advantage.

In the present case, epoch-making mechanics were also applied for uprighting and distalizing the second molar. First, two step bends, whose distance was $2 \mathrm{~mm}$ longer than the distance between the second premolar bracket and the second molar tube, were incorporated into an archwire. When the archwire with the constricted two step bends was engaged, a compression force, namely, a distal force to the second molar, was produced, which could yield the space for positioning of the first molar. Since two step bends with archwires of a larger cross section would produce an extremely heavy force, a $0.016 \times 0.016$-in square NiTi archwire was used. By applying a distal force $(\mathrm{F})$ to the second molar, a distal tipping moment (M) based on the product of the distal force magnitude and the perpendicular distance from a line of action of the force to its CR (h) was simultaneously produced, as shown in Figure 5B.

The cantilever mechanics would generate not only an uprighting moment, but also an extrusive force that could often cause occlusal interference with the maxillary molar on the opposite side. On the other hand, the uprighting mechanics using a compression force with two step bends or an open-coil spring could minimize the magnitude of an extrusive force, which may be indicated for the second molar in the present case since it was slightly inclined and did not require further eruption.

Since insertion of an open-coil spring into a straight archwire without step bends could generate occlusal interference (Figure 5A), the two step-bend mechanics was used. When the archwire with the constricted two step bends was engaged in the brackets, the wire portion between the two step bends was deformed inferiorly toward the gingiva. Consequently, vertical clearance between the maxillary and mandibular molars could be obtained, which could also prevent the molar tube from falling off.

\section{CONCLUSION}

Two different mechanics were used for uprighting the mandibular first and second molars. The cantilever mechanics designed in this case report was found to be effective for correction of a severely tipped and deeply impacted molar. Placement of a miniscrew between the canine and first premolar with a long cantilever mechanics allowed efficient uprighting of the molar by producing a large distal tipping moment in relation to an extrusive force.

On the other hand, the mechanics using a compression force with two step bends incorporated into a NiTi archwire was considered to be indicated for cases in which the molar was slightly tipped and extrusion and the resultant occlusal interference should be prevented. Using the different designs of uprighting mechanics properly depending on the stage of tipped molars would be the key to successful treatment.

\section{CONFLICTS OF INTEREST}

No potential conflict of interest relevant to this article was reported.

\section{REFERENCES}

1. Dachi SF, Howell FV. A survey of 3,874 routine fullmonth radiographs. 11. A study of impacted teeth. Oral Surg Oral Med Oral Pathol 1961;14:1165-9.

2. Chu FC, Li TK, Lui VK, Newsome PR, Chow RL, Cheung LK. Prevalence of impacted teeth and associated pathologies--a radiographic study of the Hong Kong Chinese population. Hong Kong Med J 2003;9:158-63.

3. Keris EY, Bozkaya S, Öztürk M, Güngör K. Prevalence and characteristics of impacted permanent molars in a Turkish subpopulation. J Oral Maxillofac Radiol 2016;4:45-9.

4. Roberts WW 3rd, Chacker FM, Burstone CJ. A segmental approach to mandibular molar uprighting. Am J Orthod 1982;81:177-84.

5. Kuhlberg AJ. Cantilever springs: force system and clinicalapplications. Semin Orthod 2001;7:150-9.

6. Lee KJ, Park YC, Hwang WS, Seong EH. Uprighting mandibular second molars with direct miniscrew anchorage. J Clin Orthod 2007;41:627-35.

7. Shapira Y, Borell G, Nahlieli O, Kuftinec MM. Uprighting mesially impacted mandibular permanent second molars. Angle Orthod 1998;68:173-8.

8. Majourau A, Norton LA. Uprighting impacted second molars with segmented springs. Am J Orthod 
Dentofacial Orthop 1995;107:235-8.

9. Fu PS, Wang JC, Chen $\mathrm{CH}$, Huang TK, Tseng $\mathrm{CH}$, Hung CC. Management of unilaterally deep impacted first, second, and third mandibular molars. Angle Orthod 2012;82:565-71.

10. Resch D. Clinical management of unilaterally impacted mandibular first and second molars. J Clin Orthod 2003;37:162-4; quiz 148.

11. Mehrotra R, Mehrotra A, Mistry J. Management of unilaterally impacted permanent mandibular first, second and third molars. J Ind Orthod Soc 2014;48:419-28.

12. Lau CK, Whang CZ, Bister D. Orthodontic uprighting of severely impacted mandibular second molars. Am J Orthod Dentofacial Orthop 2013;143:116-24.

13. Raveli TB, Raveli DB, de Mathias Almeida KC, Pinto ADS. Molar uprighting: a considerable and safe decision to avoid prosthetic treatment. Open Dent J 2017;31:466-75.

14. Fu PS, Wang JC, Wu YM, Huang TK, Chen WC, Tseng YC, et al. Impacted mandibular second molars. Angle Orthod 2012;82:670-5.

15. Sawicka M, Racka-Pilszak B, Rosnowska-Mazurkiewicz A. Uprighting partially impacted permanent second molars. Angle Orthod 2007;77:148-54.

16. Magkavali-Trikka P, Emmanouilidis G, Papadopoulos MA. Mandibular molar uprighting using orthodontic miniscrew implants: a systematic review. Prog Orthod 2018;19:1.

17. Park HS, Kyung HM, Sung JH. A simple method of molar uprighting with micro-implant anchorage. J Clin Orthod 2002;36:592-6.

18. Giancotti A, Muzzi F, Santini F, Arcuri C. Miniscrew treatment of ectopic mandibular molars. J Clin Orthod 2003;37:380-3.

19. Giancotti A, Arcuri C, Barlattani A. Treatment of ectopic mandibular second molar with titanium miniscrews. Am J Orthod Dentofacial Orthop 2004; 126:113-7.

20. Barros SE, Janson G, Chiqueto K, Ferreira E, Rösing C. Expanding torque possibilities: a skeletally anchored torqued cantilever for uprighting "kissing molars". Am J Orthod Dentofacial Orthop 2018;153:588-98.

21. Mah SJ, Won PJ, Nam JH, Kim EC, Kang YG. Uprighting mesially impacted mandibular molars with 2 miniscrews. Am J Orthod Dentofacial Orthop 2015;148:849-61.

22. Nienkemper M, Ludwig B, Kanavakis G, Pauls A, Wilmes B, Drescher D. Uprighting mesially impacted lower third molars with skeletal anchorage. J Clin Orthod 2016;50:420-6.

23. Melo AC, Duarte da Silva R, Shimizu RH, Campos D, Andrighetto AR. Lower molar uprighting with miniscrew anchorage: direct and indirect anchorage. Int J Orthod Milwaukee 2013;24:9-14.

24. Miyawaki S, Koyama I, Inoue M, Mishima K, Sugahara T, Takano-Yamamoto T. Factors associated with the stability of titanium screws placed in the posterior region for orthodontic anchorage. Am J Orthod Dentofacial Orthop 2003;124:373-8.

25. Cheng SJ, Tseng IY, Lee JJ, Kok SH. A prospective study of the risk factors associated with failure of mini-implants used for orthodontic anchorage. Int $\mathrm{J}$ Oral Maxillofac Implants 2004;19:100-6.

26. Kravitz ND, Kusnoto B. Risks and complications of orthodontic miniscrews. Am J Orthod Dentofacial Orthop 2007;131:S43-51.

27. Lai TT, Chen MH. Factors affecting the clinical success of orthodontic anchorage: experience with 266 temporary anchorage devices. J Dent Sci 2014;9:4955.

28. Chang $\mathrm{CH}$, Lin JS, Roberts WH. Ramus screws: the ultimate solution for lower impacted molars. Semin Orthod 2018;24:135-54. 